\title{
Communication-based behaviour support for adults with intellectual disabilities receiving dental care: A focus group study exploring dentists' decision-making and communication
}

\author{
Caoimhin Mac Giolla Phadraig \\ Dublin Dental University Hospital, Ireland; \\ Trinity College Dublin, Ireland
}

\section{Colin Griffiths}

Trinity College Dublin, Ireland

\section{Philip McCallion}

Trinity College Dublin, Ireland;

Temple University, USA

Date accepted: 28 September 2017

\section{Mary McCarron}

Trinity College Dublin, Ireland

\section{June Nunn}

Dublin Dental University Hospital, Ireland;

Trinity College Dublin, Ireland
Journal of Intellectual Disabilities

$1-15$

(C) The Author(s) 2017

Reprints and permission:

sagepub.co.uk/journalsPermissions.nav

DOI: $10.1|77 / 17446295| 7738404$

journals.sagepub.com/home/jid

@SAGE

\begin{abstract}
A better understanding of how communication-based behaviour supports are applied with adults with intellectual disabilities may reduce reliance on restrictive practices such as holding, sedation and anaesthesia in dentistry. In this study, we explore how communication is used by dentists who provide treatment for adults with intellectual disabilities. A descriptive qualitative study, adopting synchronous online focus groups, was undertaken with six expert dentists in Ireland. Members were contacted again in pairs or individually for further data collection, analysed using thematic content analysis. Two relevant categories emerged from the data, relating to the selection and application of communication-based behaviour support for adults with intellectual disabilities. Decision-making processes were explored. Building on these categories, a co-regulating process of communication emerged as the means by which dentists iteratively apply and adapt communicative strategies. This exploration revealed rationalist and intuitive decision-making. Implications for education, practice and research are identified.
\end{abstract}

\section{Keywords}

intellectual disability, behaviour support, dentistry, focus group

\section{Corresponding author:}

Caoimhin Mac Giolla Phadraig, Department of Child and Public Dental Health, Dublin Dental University Hospital, Trinity College Dublin, Dublin 2, Ireland.

Email: macgiolla@dental.tcd.ie 


\section{Introduction}

Dentists face a dilemma: They know that dental care is a beneficial process, which is needed to promote health and function. They also know that it allows assessment, prevention and management of oral disease and pain. Yet, it is inherently invasive and aversive. Dentists, by necessity, task their patients to cope with difficult dental procedures. This difficulty is emphasized for certain groups, such as children, adults with dental phobia and those with developmental disabilities, for whom even the most basic dental procedures like visual examination or entering the surgery can be almost impossible. Therefore, dentists are challenged to support their patients so that dental treatment can be completed successfully, while minimizing discomfort, maximizing learning of coping skills for possible future episodes of treatment and optimizing the experience of dental care. In dentistry, this has come to be called behaviour support.

Unfortunately, there is little in the literature to help dentists to apply behaviour support specifically with adults with intellectual disabilities (Newton, 2009). So, dentists treating adults with intellectual disabilities have come to develop a broad but ill-defined range of behaviour supports to help their patients with intellectual disabilities to receive dental care. These behaviour supports can be broadly considered as communication-based, environmental, physical and pharmacological behaviour supports, each consisting of multiple strategies that can be adopted to achieve successful outcomes for patients. Pharmacological behaviour supports, consisting mainly of conscious sedation and general anaesthesia, and physical behaviour supports, such as clinical holding and restraint, are often applied for this group of patients but are restrictive and limit a patient's potential for learning suitable coping skills. On the other hand, communicationbased behaviour supports, including general verbal, para-verbal and non-verbal communication skills (communicative strategies), as well as specific behavioural, distraction, expectancy, relaxation and cognitive strategies, are less restrictive. These strategies are therefore generally preferred in part because they promote principles of minimal restriction and offer an opportunity for people with intellectual disabilities to learn and develop independent coping skills (Kemp, 2005; Newton, 2009), among many other benefits. However, dentists have little understanding of their principles and are indiscriminate in their use (Humza Bin Saeed et al., 2012; Kawia et al., 2015). On the other hand, dentists probably apply such techniques unbeknown to themselves (Marks, et al., 2012). This emphasizes the subtlety and complexity of the selection and application of such techniques.

Overall, a better understanding of communication-based behaviour support should reduce reliance on restrictive practices, perhaps rendering them unnecessary and even unethical (Lyons, 2009; Newton, 2009; Sturmey, 2015). Despite their importance and potential benefit, there is little known about how communication-based behaviour supports should be applied with adults with intellectual disabilities. Therefore, research is needed to refine their application and use. In this exploratory study, we explore how communication-based behaviour supports are selected and applied for adults with intellectual disabilities to receive dental care in Ireland.

\section{Research question}

How do dentists select and apply communication-based behaviour support strategies to help adults with intellectual disabilities to receive dental treatment? 


\section{Methods}

\section{Design and methodological orientation}

We undertook an exploratory, descriptive qualitative study using data from online, synchronous, focus groups and interviews, sequentially. Data were analysed using qualitative thematic content analysis, as described by Burnard et al. (2008). Ethical approval was granted from the School of Dental Science Ethics Committee, Trinity College Dublin.

\section{Sample}

Six dentists acted as informants, sampled from expert dentists who have extensive experience and unique perspectives of supporting adults with intellectual disabilities to receive dental care within an Irish context. This technique shares features with key informant sampling (Marshall, 1996). Social media was utilized to notify potential participants of the research project. Given the highly specific and limited population of interest, we targeted the Irish Society for Disability and Oral Health and Project SMILE Ireland social media sites. Due to the recognized difficulties associated with social media recruitment for online focus groups, we encouraged snowballing once participants agreed to participate (Boydell et al., 2014). Inclusion criteria, published online, specified that dentists with experience of working with adults with intellectual disabilities were sought for a focus group study exploring non-restrictive behaviour support for adults with intellectual disabilities. To avoid pressure on potential participants and to fulfil obligations for ethical approval of this study, a university administrator acted as an independent contact between researchers and potential participants to mediate possible participation and to share study information prior to contact with the research team. Eight dentists responded, seven of whom met the inclusion criteria. All seven had extensive experience with this patient group and were invited to attend an online focus group, which one could not attend. A final group of six dentists participated, all of whom had extensive experience/training in treating people with disabilities. Three were trained to the level of a postgraduate diploma in special care dentistry, one held a diploma in conscious sedation in dentistry and two were trained as specialists. One ran a private practice for patients with disabilities and all others worked in public dental services. All were members of the Irish Society for Disability and Oral Health. Geographically, participants came from across Ireland from a mix of rural and urban areas.

\section{Data collection}

Sequential, reconvened (or repeated) focus groups have been used on occasion to deepen the sharing of knowledge on health-related topics. Repeating focus groups may, among other benefits, potentially improve reliability while eliciting 'a more in-depth understanding of the array of perceptions, beliefs, attitudes, and experiences held by participants' (Jacklin et al., 2016). Serial interviews present a more established method understood to deliver similar advantages (Murray et al., 2009). Data in this study came from sequential focus groups/interviews with the same group of participants. This approach was not selected a priori in this project, rather it was adopted to meet the shifting conditions of the real-world research being conducted. Participants had originally planned to meet in a face-to-face focus group at an annual conference. However, the conference programme overran meaning that most participants were unable to attend. Given the geographic dispersion of participants, the researcher explored the utility of interviews and synchronous or asynchronous online focus groups. A synchronous online focus group was selected because it 
Journal of Intellectual Disabilities $X X(X)$

offered the advantages of focus group methodology while addressing the difficulties in convening such a geographically dispersed information-rich group (Janghorban et al., 2014). Other research teams have decided to use online media to address similar difficulties (Deggs et al., 2010). At the initial level of data collection, the researcher found that an online focus group also presented barriers for the group. While participants were visible and audible to each other, the absence of material non-verbal communication and real-life atmosphere meant that discussion was somewhat stunted at times. This meant that the facilitator's role as 'traffic cop' was more involved than would have been the case in face-to-face focus group sessions. This diminished the depth of understanding that researchers hope to find from intra-group dynamics. In response, following this focus group, it was decided to return to participants to increase the depth and breadth of exploration of the research topic and give time for narrative accounts to fully unfold. Serially collecting data among the same participants has previously been shown to carry such advantages (Jacklin et al., 2016; Murray et al., 2009).

In this way, participants in this study initially met as a focus group online to discuss behaviour support for adults with intellectual disabilities. An open schedule was used for this synchronous online focus group with a focus on aspects of communicative support rather than specifically defined 'behaviour management techniques'. The focus group concentrated mainly on members' own applications but did offer reflections of other dental professionals', carers' and families' support skills too. Data from this initial event were analysed inductively. This led to the development of a semi-structured schedule for further data collection. Two further online groups of two members each and two individual interviews involving the same participants from the initial focus group ensued, using this semi-structured interview schedule. Focus groups and interviews were undertaken online using video- and audio-enabled programmes (FUZE ${ }^{\circledR}$ ). Transcripts were generated using audio-only recordings.

\section{Data analysis}

Using thematic content analysis (Burnard et al., 2008), open coding was undertaken by CMGP and subsections were checked with $\mathrm{CG}$, with $\mathrm{JN}$ acting as arbiter. The data were then recoded and refined using the constant comparative method throughout, leading to the development of the final coding framework. Codes were clustered conceptually into subcategories and categories and from there data were separated by category and subcategory for interpretation. Microsoft Word and Excel enabled data coding, clustering and analysis.

\section{Rigour of analysis}

Member checking was carried out with two participants (all were invited) thereby giving participants a chance to react to both the data and the final narrative, adding credibility to the analysis. This involved a discussion of the analytic process, illustrated using specific quotes, and a review of the models arising from the analysis, to confirm their accuracy, from participants' perspectives. Peer debriefing was also undertaken between CG and CMGP to avoid lone researcher bias and enhance rigour (Long and Johnson, 2000). The reader is encouraged to consider the author's prejudices and their possible impact on the analyses that follow (Long and Johnson, 2000). CMGP acknowledged often encountering the referral, by primary care dentists, of adults with intellectual disabilities for sedation or general anaesthesia when it was possible to deliver oral care to the individual with intellectual disabilities, if only the most basic of communication-based behaviour supports had been provided with skill, confidence and knowledge. The researcher had also 


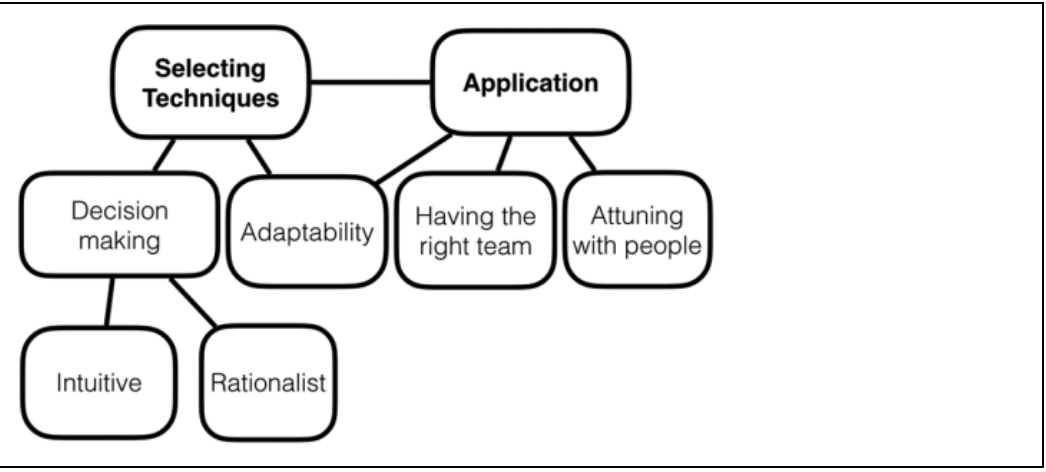

Figure I. Emergent categories and subcategories.

observed inappropriate selection and poor application of techniques among dental trainees. The researcher utilized peer review by other team members to manage any potential impact on analysis and interpretation.

\section{Results}

\section{Framework, codes and categories}

Figure 1 summarizes the categories and subcategories that emerged in this study focusing on the selection and application of communication-based behaviour support. Together, these data represent a continuous, iterative communicative process of assessment, application, reassessment and adaptation of communicative strategies.

\section{Rational and intuitive decision-making}

Participants demonstrated highly individualized decision-making processes when selecting specific strategies. Each person relied on a varying balance of rational and intuitive decision-making, one respondent observed that:

it can be ... an organised process or a disorganised process, if that makes sense?. (Participant 2)

Drawing from a rational perspective, participants often referred to their initial assessment process, whereby they matched their approach to the patient by bringing together information from a broad range of sources. Participant 5 captured this process concisely:

So its knowledge and what you see personally in front of you, and what you are told: what they are like and you try and get the bigger picture of the whole thing, before you try anything.

Sources of information included previous experience with the patient, observing/considering carer interactions with the individual, assessment of ability, preferences and discussion with the patient and those who support them, participant 5 continued:

I think the most important thing... is to speak to the person, the patient, and see what they feel comfortable with. 
Apart from diagnoses associated with specific behavioural profiles, such as Fragile X syndrome or autism, respondents considered the patient's diagnosis secondary to personalized information collected before and then during the encounter.

This structured process was juxtaposed by a selection process that was also naturalistic and subconscious, as can be observed by participant 4 who emphasized the empathic and intuitive nature of the process:

You are reading the person from the vibes they are giving off.

These intuitive processes varied and were more prominent for some group members. Participant 6 described how she intuitively arrive at a decision:

Ya know, it's not something I consciously think. It is just something that you would instinctively and automatically fall into.

Upon further discussion, however, it appeared that many seemingly intuitive processes relied upon assessment of non-verbal messages communicated by the patient, participant 4 expanded on this noting that:

When I'm assessing ... the minute they walk through the door ... I'm looking, aware of what's going on, looking at the reactions of the carers, picking up little things, the movements, the way they ... Just the whole demeanor... As I talk, just the reaction, the whole experience of coming into the surgery, I'm just looking all the time, picking up all the time and learning all the time.

Given the significance of non-verbal communication, intuition was most prominent in perioperative assessment and reassessment when the patient could be observed, as participant 2 captures:

Then you are moving from that pre-assessment, where you are judging them based on information, you are getting to reading their body language, their sense of anxiety, you know, very physical signs, I suppose.

Participants explored the processes underlying this intuition, leading participant 5 to conclude that it may actually represent a more structured, transferable process than at first sight:

I would have thought that [deciding a behaviour support strategy] happened naturally, but when I think about it, there probably is a certain amount of thought process that you are going through in your head and you're ticking certain boxes, unknown to yourself ... and making a decision.

It is important to note that while strategy selection was reported as led by the dentist, patients communicated their preference either expressly or through their non-verbal or behavioural cues and thereby controlled the selection process to varying degrees, as this example of a patient who preferred to be treated by a man illustrates:

you just knew, the way she was ... automatically going towards him and not coming towards me ... if that's the person that she wants to go for, then let her. (Participant 5)

Respondents noted that formal postgraduate education promoted rational rather than intuitive approaches to decision-making, as captured by participant 2's comment: 
If you get the training, that will certainly organise your process accordingly, and if you get the experience and never have the training, you will probably carry on with a certain level of modification over time but not a thought out process: I think, probably, a subconscious modification.

It appeared to some participants that the rational approach, where strategies were purposefully selected and applied in an organized manner and assessed explicitly, offered a structure to the support process and promoted reflective practice:

There is benefit to training "cause it often makes you more aware of the structured approach, where you are sort of able to evaluate better when you are [supporting behaviour]. Sometimes when you are just going on experience you are frantically trying to find different things, but not able to evaluate what worked and what didn't work or why it worked for that individual.' (Participant 1)

Adaptability in selecting strategies. Participants described an adaptable approach by detailing how they altered their approach to behaviour support according to the specific situation as it developed:

I adapt to the situation. The situation can change ... and you change accordingly, you know ... to suit the situation...(Participant 4)

This adaptation occurs along with changing expectations from treatment. The group recognized this flexibility of approach as a fundamental skill:

I think that an important aspect... is that [it] is very dependent on flexibility and ability of the clinician... [to] be willing to change their attitudes towards behaviour mid-treatment. (Participant 2)

The adaptation process appeared to work through the dentist attuning to the person being treated and continuously assessing the interaction and the treatment. The group reported a reflexive process whereby the strategies selected changed based on changes within and between patients: 'I think that it is an on-going process ... no two patients are the same they are all different and as you move through the treatment plan and move through the process you may change and adapt' (participant 4).

\section{Applying communication-based behaviour supports}

Participants discussed how their communication-based behaviour support strategies were applied. They focused on communicative strategies rather than behavioural or other formalized approaches.

Attuning: Supporting behaviour by attuning with patients. The group recognized the need to engage with people as a foundation for effective support, enabling connection, rapport, the application of behavioural interventions and ultimately cooperation:

There has to be an initial level of communication built up with the person before you start any of those styles of tell-show-do, or any of that, ya know? (Participant 2)

This connection was often made subtly, and in the context of a positive atmosphere, purposefully crafted to increase the likelihood of successful dental visits:

The aim is to make the patient happy; to take the threat out of the environment; to deliberately make the patient like you and like coming. (Participant 6) 
To illustrate this, one participant suggested a process of syncing his being, attention and engagement with his patients, rather than using specific behavioural strategies:

You could call it behaviour management but it is just interacting with people and making them comfortable and actually like being there. (Participant 6)

Other approaches, which contribute to attuning, included playing together and sharing fun. As one participant said: 'We are deliberately creating that atmosphere "the good craic atmosphere" for ourselves, as well as our patient.' (Participant 6)

Adaptability: The role of adaptability in behaviour support. Participants recognized the importance of being versatile in how they communicated with patients. Some, like participant 1, applied different personae depending on the support needs of the patient:

I think that's very important because who you are with the patient can change, not fundamentally, but you can make jokes with some patients and other patients will be more serious, ya know.

Participants repeatedly described ways of switching tack if the technique they applied was not working. This might involve the dentist changing their behaviour:

Where you are using bargaining or ... positive reinforcement: molly coddling and then you say: Right!

This isn't particularly working. It becomes a lot more directive and setting limits. (Participant 1)

Other examples of adaptability involved the dentist substituting with a colleague (swapping out), having assessed a lack of progress in supporting the patient. This substitute clinician may be used specifically because they are the preferred clinician or to specifically attempt an alternative approach:

You may fail on all grounds and it might not be just a case of changing the behavioural approach but changing the clinician. (Participant 2)

Having the right team. Expanding this focus on the persons involved, participants understood that having the right team in place to support the patient was vital to achieve success for the patient. Equally, having the wrong team was seen as limiting, as participant 5 warned while discussing dental nurses in their team:

[If] you are given somebody ... who has no intent ... or no experience ... that can mean that your clinic is a complete waste of time then. (Participant 5)

The importance of their role in developing their team to more effectively support people with intellectual disabilities was clear. The team included specialist colleagues within their referral networks, the wider dental team and those who support the patient to come to the dentist such as carers who accompany the person to the dentist:

See the carer, that comes in and you are very successful, then you just request that, the next time that that patient comes in, that that carer comes in with them. (Participant 5)

The skill and confidence of the team, and not just the participant, was seen as crucial: 
the two [nurses] we work with ... are very confident and I have experienced in the past when other girls have come in, and they aren't confident, it can change the dynamics in the room and it may not be as successful as it could have been, ya know? (Participant 4)

Above, the data explain how this group of participant dentists select and apply communicationbased behavioural supports for use with people with ID.

\section{Discussion}

Three aspects emerge from these data for discussion: decision-making in selection, the application of strategies and the communicative process within which these occur.

\section{Decision-making}

Participants adopted an individualized iterative process when selecting communication-based behaviour supports, by considering a wide range of information sources, mirroring other areas of healthcare decision-making (Aitken, 2003). Members of the group used both rationalist and intuitive decision-making processes to select these approaches. These cognitive processes occurred alongside each other, allowing the dentist to move from assessment and application to reassessment and adaptation. Among the group, it seemed that both decision-making processes occurred simultaneously, to greater or lesser degrees, as pointed out in member check. This reflects Epstein's concept that parallel processes occur with varying degrees of interaction between conscious rationality and subconscious experiential processes from person to person and situation to situation (Epstein, 2008).

The rationalist approach assumes explicit analytical activity by the decision maker. Here, it involved pre-assessment of the patient based on information from carers, parents and the patients themselves. This analysis led to the selection of a communicative strategy that was then explicitly assessed, for example, by reading non-verbal and behavioural cues, before adapting the approach purposefully. The rational approach, espoused especially by those members with advanced postgraduate training, seemed to give a sense of identifiable, measurable outcomes and decisionmaking. Broader research suggests that structured approaches like this are preferred for behaviour support selection (Alshammasi, 2014). Data and member checking supported this.

This is not to dismiss intuitive processes. This study shows that observation and experience intuitively informed the selection process too. In this way, dentists went along with the situation in an organic manner, without explicit selection or assessment of their strategies. Participant opinion recognizes the importance of instinct and emotional skills in this regard, for example, Raposa compels readers to 'be guided by instinct and creativity, rather than by strict reasoning' (Raposa, 2009). Intuitive judgement is said to be the translation of experience into action (Klein, 2003) and is a recognized and accepted approach to decision-making, which may even reflect expertise in a field, particularly as a practitioner moves from novice to expert (Aitken, 2003). In this instance, it seemed to be different. Rather, intuition was reportedly applied in the absence of training, possibly an outcome of insufficient coverage of this topic during undergraduate education.

On further reflection, the instinctive process used by this group of experts was seemingly based on structured steps such as assessment of patient-related factors, awareness of non-verbal communication, applying previous learning to new situations and reflective practice. Perhaps these steps are largely ill-defined by those who use them 'intuitively'. Theory supports this assumption. Intuition, it seems, is built on the use of a 'sound, rational, relevant knowledge base in situations 
that, through experience, are so familiar that the person has learned how to recognise and act on appropriate patterns' (Cert and Wilcockson, 1996). This is important because receptive communication skills, knowledge of support techniques and reflective practice skills are learnable attributes. By recognizing these steps, it is possible to consider apparently non-transferable traits, implied by intuition, as learnable skills.

\section{Applying skills}

When supporting behaviour, participants focused on communicative rather than strictly behavioural strategies. They highlighted sharing attention and engagement with their patients to offer support. It is clear that these dentists actively promote alignment emotionally and behaviourally. In this way, dentists attune with their patients leading to more successful outcomes. Griffiths has previously identified attuning as a natural means of promoting cooperation and empathy between care provider and people with intellectual disabilities (Griffiths and Smith, 2016). In this sense, communication can be viewed as a broad transaction between dentists and patients with intellectual disabilities, which allows each to 'tune in' with each other (Roberts, 2005). This ties in with advice from Kemp (Kemp, 2005), who suggests that dentists adopt a humanistic approach to respect the dignity of the patient, and that of Peltier, who suggests that dentists should show a genuine interest in their patients with disabilities (Peltier, 2009).

Aligned somewhat with the concept of rapport, the importance of dentist interaction to increase patient's acceptance of dental care has been previously reported among non-disabled populations (Gale et al., 1984). In the current study, this group saw the value of connecting with their patients. They repeatedly referred to affinity-seeking behaviours, where they actively aimed to generate positive feelings towards themselves from their patients (Bell and Daly, 1984). Respondents also noted that they acted in their role as a behaviour guide contingently, with the option to adapt according to response. Response options included changing tack, for example, changing persona from supportive to directive, or the use of alternative dentists, for example, 'swapping out', or adjuncts such as sedatives. Teamwork was also noted as an important aspect of care, reflecting the assertion, embodied within AAPD guidelines, that the wider clinical team acts as an extension of the dentist in behaviour support and communication (American Academy of Pediatric Dentistry, 2015). Recent guidance for orthodontists, for example, highlights the need for flexibility and teamwork to facilitate care for people with disabilities (Rada et al., 2015). The data collected from this group of experts confirmed that having the 'wrong' team can have an equally important (negative) impact on the outcome of dental care.

\section{Co-regulating dynamic communication for supporting behaviour}

The selection and application of support techniques involved the dentist iteratively assessing the situation and applying a strategy in response, then reassessing and adapting this approach. Exploring this interaction, a process of cyclical communication between patient and dentist occurred. It should be noted that this occurred within a larger context involving, for example, situation, environment, carers, family and dental nurse.

The description of how participant dentists selected and applied support techniques suggests a communicative model whereby the dentist and patient co-regulate continuously, by sending and receiving messages simultaneously, but with roles of receiver and sender of messages predominating alternately, depending on the specific function of communication (e.g. assessment/ reassessment or application/adaptation). To expand, when the dentist assesses the need for a 


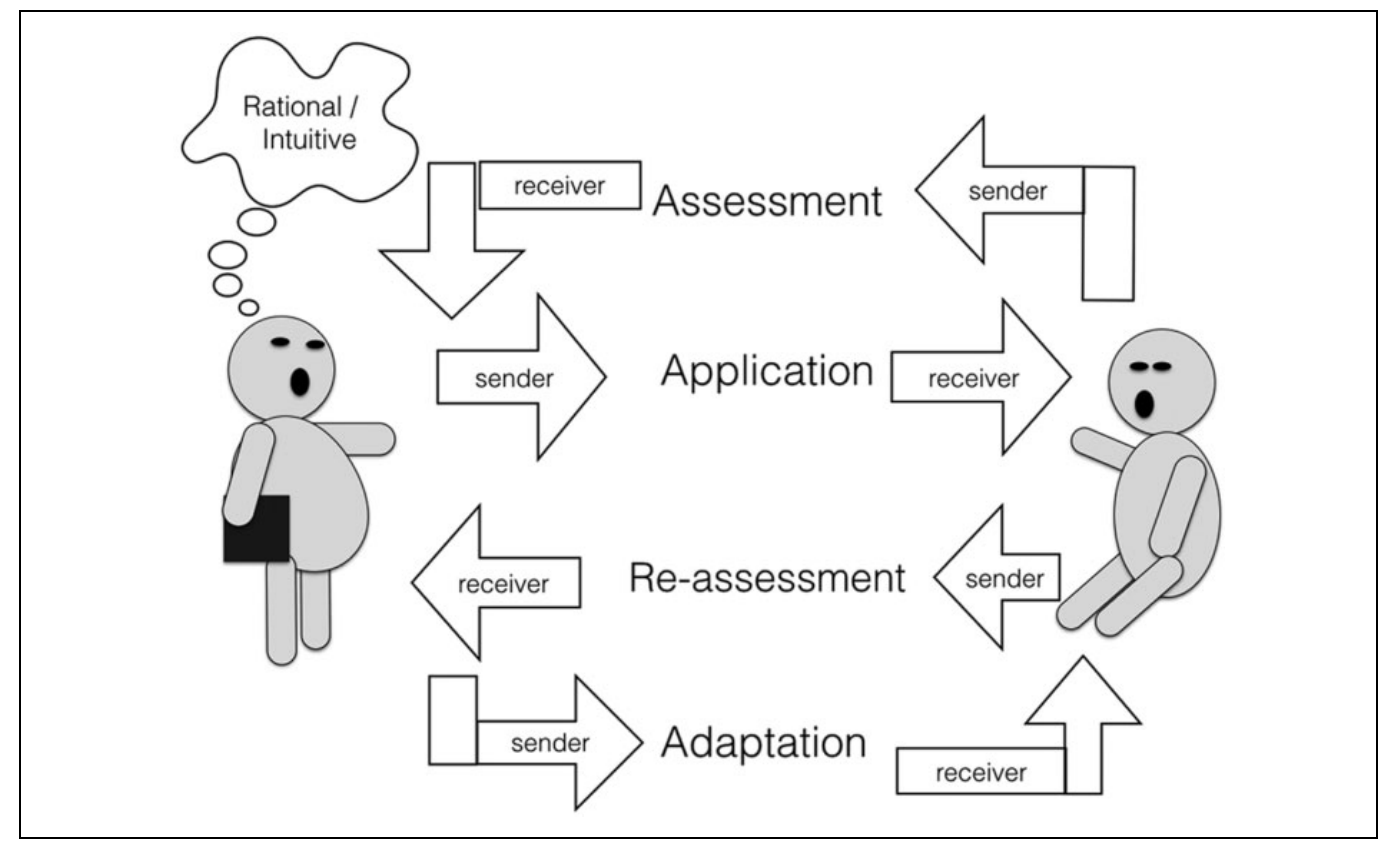

Figure 2. Co-regulating dynamic communication for supporting behaviour of adults with intellectual disabilities. Note: While this illustration separates discreet steps in the process, dynamic communicative support involves cyclic and continuous sending and receiving of messages before, during and even after behaviour support. Communicative roles predominate depending on the specific step and communicative function.

behaviour support strategy, either intuitively or rationally, receptive communication skills predominate, for example, by identifying patient preference and reading non-verbal and behavioural cues. The dentist's expressive communication skills then come to predominate in applying their communicative strategy (e.g. by attuning, seeking affinity or applying formal approaches like TellShow-Do). In applying such techniques, the sender (dentist) receives feedback (using receptive communicative skills) from the patient (applying their expressive skills). As Figure 2 illustrates, the dentist and patient accordingly attune their communication, in a co-regulating manner, by assessing and applying communicative strategies, which are in turn reassessed and adapted.

This dynamic, ongoing interaction involves communicators interdependent in a circular and continuous process and acting as both receiver and sender of messages using multiple indiscrete channels (verbal, non-verbal and behavioural cues). This reflects, in ways, a continuous processing model of communication (Fogel, 1993), whereby dentist and patient co-regulate as part of a continuous, dynamic process, rather than a simply transactional interaction (Barnlund, 1970). While concepts of reciprocation and iterative interaction in dentist-patient communication are numerous (British Society for Disability and Oral Health/Faculty of Dental Surgery of Royal College of Surgeons of England, 2012; Sondell and Soderfeldt, 1997), this model of dentist-patient communication, as presented, simplifies the communicative behaviour support interaction so as to understand the need to be clear in how dentists express themselves holistically and to 'listen' objectively and subjectively to the wide range of messages sent by patients with intellectual disabilities and adapt their communicative strategy accordingly. 
Typically, when giving advice to dentists regarding communication with people with disabilities, there is a tendency to focus on how the dentist can improve their expressive communication rather than receptive skills. For example, Peltier very helpfully recommended communicating with an appropriately slow pace, careful selection of specific positive language and the avoidance of specific negative words, a calming tone of voice and alignment of the entire office staff (Peltier, 2009). Furthermore, focus group members were concerned far more with non-verbal communication, possibly reflecting the frequency of communication impairments noted in this specific population.

This study adds to our understanding by highlighting the need to focus practice and training for dentists on both expressive and receptive, as well as verbal and non-verbal communicative, skills.

\section{Methodological issues}

Focus groups. Repeated focus group sessions can impact recruitment and retention of participants due to the time commitment required (Morgan et al., 2010). Therefore, we facilitated participants by allowing interviews and smaller groups to ensure that all participants had the opportunity to expand the discourse. Synchronous focus groups often take the form of 'chat-room' style fora (Boydell et al., 2014; Jacklin et al., 2016). In this study, the group used videoconferencing software. The fact that the group met online did seem to initially stifle the flow of conversation, leading to regular facilitator involvement to redirect or probe. However, it also ensured, naturally, that there was no overlapping talk and gave 'centre stage' to talking participants as their image enlarged while talking. Online focus group interviews necessitate access to high-speed Internet, familiarity with online communication and digital literacy (Janghorban et al., 2014). This only created issues for one participant who cut out and rejoined the group a number of times necessitating repeated 'catch ups'. As it happened, this offered opportunity for confirmation and real-time member checking but it did impact flow. The software also allowed real-time sharing of visual cues. Later, transcription was at times difficult due to 'line drops' from time to time. However, the online aspect was crucial to completion of this project and was justified as the advantages outweighed the disadvantages.

Sample size and saturation issues. This study began with an inductive approach and the data therefore were rather broad. This study presents the data relating to the application and selection of support techniques but the group did also consider the learning of skills and reasons for applying strategies. Correspondingly, this research was exploratory and did not attempt to present a comprehensive picture of the phenomena it describes. The small sample also influenced the potential for saturation but reflected that these dentists are a small, information-rich, geographically dispersed population. As Mason suggests, there are aspects of this study that supported the use of a smaller sample size (Mason, 2010). Firstly, participants are a homogenous group of highly skilled experts. In one study of eight highly skilled practitioners' clinical decision-making, the authors suggested that expertise in the chosen topic can reduce the number of participants needed to produce rich data (Jette et al., 2003). Given the breadth of data here, this study supports that assertion. Secondly, studies that use multiple, in-depth interviews with the same participant have less reliance on larger samples (Lee et al., 2002). We did not attempt to achieve saturation of themes or concepts in this study, nevertheless, it can be assumed that a larger sample would have given a broader narrative.

Group member issues. Member checking was useful because participants, in confirming the overall analysis, informed a discussion that followed on the relationship between rational and intuitive 
decision-making by dentists. Given the limited access to education in special care dentistry in Ireland, all participants had either undergraduate or postgraduate ties to Trinity College, Dublin where the research team is based and this may also have influenced the responses given by participants.

\section{Conclusions}

Expert dentists were found to rely on rationalist and intuitive decision-making processes when applying communication-based support strategies with adults with intellectual disabilities. In applying those skills, the ability to attune, work as a team and be versatile were all seen to be important. A highly adaptable, versatile co-regulatory communicative process allowed for assessment, application, reassessment and adaptation of communicative strategies. Within this model, emphasis on receptive and expressive communication alternated, depending on stages within the communicative support process. Non-verbal and behavioural communications were emphasized.

There is a need to value what are clearly highly specialized clinical skills in communicationbased behaviour support. Investment needs to be made in training, both undergraduate and postgraduate, in clinical decision-making and communication with people with intellectual disabilities. Dentists should also be given the opportunity to gain experience in communication-based behaviour support to build their own skills. In practice, there is a need to recognize the role of appropriate application of what are highly skilled techniques to reduce restrictive practices among adults with intellectual disabilities in Ireland.

Further research is needed to explore how communication-based support strategies are learned and why they are used. Research into the teaching of behaviour support focusing on decisionmaking and both receptive and expressive communication skills is also needed, so that these skills can be taught at undergraduate and postgraduate levels for future generations of dentists treating people with disabilities, as this field of dentistry moves from art to science.

\section{Acknowledgement}

The authors acknowledge the time given by respondents and those who supported them over successive waves of IDS-TILDA study.

\section{Declaration of Conflicting Interests}

The author(s) declared no potential conflicts of interest with respect to the research, authorship, and/or publication of this article.

\section{Funding}

The author(s) received no financial support for the research, authorship, and/or publication of this article.

\section{References}

Aitken LM (2003) Critical care nurses' use of decision-making strategies. Journal of clinical nursing 12: 476-483.

Alshammasi H (2014) Investigating the Use of Behaviour Management Techniques with Children Undergoing Invasive Dental Treatment: An Exploratory Study. Doctoral thesis. London: University College London (UCL). 
American Academy of Pediatric Dentistry (2015) Guideline on behavior guidance for the pediatric dental patient. Pediatric Dentistry 37: 57-70.

Barnlund DC (1970) A transactional model of communication. In: Akin J, Goldberg A and Myers G (eds) Language Behavior: A Book of Readings in Communication. The Hague: Mouton, pp. 43-61.

Bell RA and Daly JA (1984) The affinity-seeking function of communication. Communication Monographs 51: 91-115.

Boydell N, Fergie G, McDaid L, et al. (2014) Avoiding pitfalls and realising opportunities: reflecting on issues of sampling and recruitment for online focus groups. International Journal of Qualitative Methods 13: 206-223.

British Society for Disability and Oral Health/Faculty of Dental Surgery of Royal College of Surgeons of England (2012) Clinical guidelines and integrated care pathways for the oral health care of people with learning disabilities. Available at: http://www.bsdh.org.uk/guidelines/BSDH_Clinical_Guidelines_ PwaLD_2012.pdf (accessed 1 February 2017).

Burnard P, Gill P, Stewart K, et al. (2008) Analysing and presenting qualitative data. British Dental Journal 204: 429-432.

Cert PE and Wilcockson J (1996) Intuition and rational decision-making in professional thinking: a false dichotomy? Journal of Advanced Nursing 24: 667-673.

Deggs D, Grover K and Kacirek K (2010) Using message boards to conduct online focus groups. The Qualitative Report 15: 1027.

Epstein S (2008) Intuition from the perspective of cognitive-experiential self-theory. Intuition in Judgment and Decision Making 23: 37.

Fogel A (1993) Two principles of communication: co-regulation and framing. In: Nadel J and Camaioni L (eds) New Perspectives in Early Communicative Development. London: Routledge, pp. 9-22.

Gale EN, Carlsson SG, Eriksson A, et al. (1984) Effects of dentists' behavior on patients' attitudes. Journal of the American Dental Association 109: 444-446.

Griffiths C and Smith M (2016) Attuning: a communication process between people with severe and profound intellectual disability and their interaction partners. Journal of Applied Research in Intellectual Disabilities 29: 124-138.

Humza Bin Saeed M, Daly B and Newton JT (2012) Knowledge and practice of behavioral management principles among dentists treating adults with learning disabilities. Special Care in Dentistry 32: 190-195.

Jacklin K, Ly A, Calam B, et al. (2016) An innovative sequential focus group method for investigating diabetes care experiences with indigenous peoples in Canada. International Journal of Qualitative Methods 15: 1-12.

Janghorban R, Latifnejad Roudsari R and Taghipour A (2014) Skype interviewing: the new generation of online synchronous interview in qualitative research. International Journal of Qualitative Studies on Health and Well-being 9: 24152. doi:10.3402/qhw.v9.24152.

Jette DU, Grover L and Keck CP (2003) A qualitative study of clinical decision making in recommending discharge placement from the acute care setting. Physical Therapy 83: 224-236.

Kawia HM, Mbawalla HS and Kahabuka FK (2015) Application of behavior management techniques for paediatric dental patients by tanzanian dental practitioners. Open Dental Journal 9: 455-461.

Kemp F (2005) Alternatives: a review of non-pharmacologic approaches to increasing the cooperation of patients with special needs to inherently unpleasant dental procedures. The Behavior Analyst Today 6: 88 .

Klein GA (2003) Intuition at Work: Why Developing Your Gut Instincts will make You Better at What You do. New York: Currency/Doubleday.

Lee DT, Woo J and Mackenzie AE (2002) A review of older people's experiences with residential care placement. Journal of Advanced Nursing 37: 19-27.

Long T and Johnson M (2000) Rigour, reliability and validity in qualitative research. Clinical Effectiveness in Nursing 4: 30-37. 
Lyons RA (2009) Understanding basic behavioral support techniques as an alternative to sedation and anesthesia. Special Care in Dentistry 29: 39-50.

Marshall MN (1996) Sampling for qualitative research. Family Practice 13: 522-526.

Marks L, Adler N, Blom-Reukers H, et al. (2012) Ethics on the dental treatment of patients with mental disability: results of a Netherlands - Belgium survey. Journal of Forensic Odontostomatology 30(Suppl 1): $21-28$.

Mason M (2010) Sample size and saturation in $\mathrm{PhD}$ studies using qualitative interviews. Forum Qualitative Sozialforschung/Forum: Qualitative Social Research 11(3). Available at: http://dx.doi.org/10.17169/fqs11.3.1428 (accessed 1 February 2017).

Morgan D, Fellows C and Guevara H (2010) Emergent approaches to focus group research. In: Hesse-Biber SN and Leavy P (eds) Handbook of Emergent Methods. New York, NY: Guilford Press, pp. 189-206.

Murray S, Kendall KC, Worth E, et al. (2009) Use of serial qualitative interviews to understand patients' evolving experiences and needs. British Medical Journal 339: 958-960.

Newton JT (2009) Restrictive behaviour management procedures with people with intellectual disabilities who require dental treatment. Journal of Applied Research in Intellectual Disabilities 22: 118-125.

Peltier B (2009) Psychological treatment of fearful and phobic special needs patients. Special Care in Dentistry 29: 51-57.

Rada R, Bakhsh HH and Evans C (2015) Orthodontic care for the behavior-challenged special needs patient. Special Care in Dentistry 35: 138-142.

Raposa KA (2009) Behavioral management for patients with intellectual and developmental disorders. Dental Clinics of North America 53: 359-373, xi.

Roberts B (2005) Promoting healthy lifestyles. In: Grant G, Goward P, Richardson M and Ramcharan P (eds) Learning Disability: A Life Cycle Approach to Valuing People. Berkshire: Open University Press, pp. 243-260.

Sondell K and Soderfeldt B (1997) Dentist-patient communication: a review of relevant models. Acta Odontologica Scandanavica 55: 116-126.

Sturmey P (2015) Reducing Restraint and Restrictive Behavior Management Practices. Switzerland: Springer. 